ORIGINAL ARTICLE

\title{
Perceptions of parents on the participation of their infants in clinical research
}

\author{
A Gammelgaard, L E Knudsen, H Bisgaard
}

See end of article for authors' affiliations

.....................

Correspondence to: A Gammelgaard, Department of Medical Philosophy and Clinical Theory, Institute of Public Health, University of Copenhagen, Blegdamsvej 3, DK-2200 Copenhagen N, Denmark; a.gammelgaard@medphil. ku.dk

Accepted 28 June 2006

Published Online First 4 July 2006

\begin{abstract}
Objective: To analyse the motivations and perceptions of parents on the participation of their infants and young children in a comprehensive and invasive clinical research study.

Methods: Semistructured qualitative interviews were conducted with 23 mothers with asthma whose infants and young children were participating in the Copenhagen Prospective Study on Asthma in Childhood. The interviews were audiotaped, transcribed and analysed using the template analysis method.

Results: Parents were motivated by altruism and by the opportunity to get their child checked regularly by medical experts to prevent the possible development of asthma. Parents found it very important that their children enjoyed their visits to the research clinic, and that they could withdraw from the study if their child started responding negatively to those visits. No apparent difference was seen in the attitude between the parents of children with lung or skin symptoms and those of healthy children.

Conclusions: It is possible to design and accomplish invasive clinical research on infants and young children in a manner that parents find ethically sound.
\end{abstract}

lints recent years, various initiatives have aimed at furthering paediatric research, as the absence of adequate studies in the paediatric population has hampered progress in the care of children. ${ }^{12}$ In the US, several laws have been enacted to make drug manufacturers test their products on children, ${ }^{3-}$ ${ }^{5}$ and in Europe, the European Research Commission has proposed granting companies testing their medicinal products on children an extended period of patent and data protection. ${ }^{6}$

There is a growing body of literature discussing specific ethical dilemmas in relation to paediatric research, such as the inclusion of healthy children in non-therapeutic research $^{27}$ and the role of children's assent and dissent in decision making. ${ }^{8}$ " Considering the ethical debate about children as research subjects, it is relevant to investigate how parents and children perceive their participation in research.

In this study, we report the perceptions of parents on the participation of their children in a birth cohort study associated with both therapeutic and non-therapeutic invasive procedures, such as sedation and lung-function testing at the age of 1 month, repeated skin tests and venepunctures. To our knowledge, this particular birth cohort study is the most comprehensive and invasive study on healthy infants and young children in recent years.

\section{METHODS \\ Participants}

Mothers whose children were participating in the Copenhagen Prospective Study on Asthma in Childhood (COPSAC) were eligible for this study. COPSAC is a singlecentre longitudinal clinical-epidemiological birth cohort study on children of mothers with asthma. Objective assessments begin at birth, with scheduled visits every 6 months and when acute symptoms manifest. Clinical outcomes comprise asthma, atopic dermatitis, allergic rhinitis, allergy, lung function and bronchial responsiveness. ${ }^{10} \mathrm{~A}$ total of 411 infants of mothers with asthma were enrolled at the age of 1 month. At the age of 3 years, $90 \%$ of the infants were still participating in the study. ${ }^{10}$

\section{Design}

Qualitative interviews were conducted with 23 mothers of children participating in COPSAC. Mothers of children from the following three categories were selected randomly from the COPSAC database:

- children without any symptoms of asthma or atopic dermatitis

- children diagnosed with asthma or atopic dermatitis

- children diagnosed with asthma and atopic dermatitis.

The sampling was based on the assumption that the motivation of parents to participate in COPSAC may be related to the burden of their child's symptoms.

Twenty eight mothers were contacted by letter. Twenty three of them agreed to participate in this study, whereas the remaining five did not participate (one was abroad, one did not wish to participate and three could not find the time for the interview). Nine of the children showed no symptoms of asthma or atopic dermatitis, six were diagnosed with asthma or atopic dermatitis and eight were diagnosed with asthma and atopic dermatitis. The children were aged between $2 \frac{1}{2}$ and 5 years at the time of the interview.

The mothers were interviewed at home (except one who was interviewed at the hospital) by AG, a bioethicist who was not otherwise associated with COPSAC. The mothers were informed that their statements would be anonymised and that the interviewer was not associated with COPSAC. Nineteen mothers were interviewed alone and four were interviewed with their partner. Using a semistructured interview guide, ${ }^{11}$ the parents were questioned about their experiences with COPSAC, their motivation for having their children participate in the study and their general attitude to clinical research on children. The interviews lasted between 25 and $45 \mathrm{~min}$ and were audiotaped, transcribed and analysed using a textual computer package (ATLAS.ti, Scientific Software Develpment GmbH, Berlin, Germany).

Abbreviations: COPSAC, Copenhagen Prospective Study on Asthma in Childhood; CRU, clinical research unit 
The method of template analysis has been described previously by Crabtree and Miller ${ }^{12}$ and King. ${ }^{13}$ The study was approved by the regional research ethics committee (KF01-123/03).

\section{RESULTS}

\section{Motivations}

Parents whose children had asthma or showed symptoms of asthma considered the 24-h access to expert medical care and the provision of what they perceived to be a coherent treatment regimen to be major advantages of participating in the study. Moreover, the regular visits to the COPSAC clinical research unit (CRU) meant that the staff was familiar with each child and his or her medical history.

The parents of children who did not show any symptoms of asthma considered COPSAC to be an opportunity to get their child checked regularly to prevent or delay the development of asthma. They perceived the study as a kind of health insurance, granting them access to medical experts in case their child developed symptoms of asthma.

As the mothers in this study had first-hand experience with asthma, they also enrolled their infants into COPSAC to benefit future generations of children with asthma. The perceived drawbacks of the study were mainly connected to the time consumed by the comprehensive test programme and the transportation to the CRU.

\section{How parents perceived COPSAC}

According to the parents, the children were generally confident about their visits to the CRU. Some parents, however, had experienced their children refusing to enter the lung-function measurement box. Such episodes caused some parents to have second thoughts about exposing their children to unpleasant procedures in connection with research, in case such experiences would make their children afraid of doctors and hospitals. None of the parents actually found that visits to the CRU gave rise to fear of white coats among their children. On the contrary, they emphasised that the staff had made a sincere effort to create a pleasant atmosphere and also emphasised that they did not put pressure on the parents or the child to complete a specific test (quotation 1, appendix). Some mothers, however, were eager to make their children cooperate in return for the service provided by the COPSAC team (quotations 2 and 5 , appendix).

None of the parents considered that the procedures of COPSAC went beyond what is ethically acceptable. Firstly, they felt confident that their children would not be harmed by any of the procedures and, secondly, they found the discomfort related to venepunctures and skin tests to be minor and temporary (quotation 6, appendix). Thus the parents did not interpret a child's momentary disapproval of venepuncture as a general veto against COPSAC. They also did not express concern regarding the genetic tests or the measurements of environmental exposures to air pollution and house dust.

The most contentious procedure was the initial lungfunction test, which required the children to be sedated for 1$2 \mathrm{~h}$ (quotations 3 and 4, appendix). Most parents were uncomfortable about sedating their healthy baby, and they also felt distressed by the sight of their sedated baby wrapped in a squeeze-jacket with a facemask, tubes and wires. Although most parents were confident that the test itself was harmless, a few parents were concerned about what might have happened if something had gone wrong. Two parents were certain that they would never again allow their children to undergo this test. None of the parents, however, felt misinformed about the test. Although some parents thought that the initial lung-function test could benefit their child, all parents in this study were well aware that some of the tests and procedures were carried out only to advance research. Generally, the families preferred to discuss the COPSAC project in its entirety, and it seemed to be less important which particular tests would help their child and which were for research (quotations 7 and 8, appendix). Unless their child refused to undergo a particular test, they would not pick and choose between the various elements of the study programme.

\section{Suggestions to improve studies on children}

The parents in this study found it important to ensure that their children enjoyed the visits to the CRU, and they also said that they would withdraw from the study if their child started responding negatively to those visits. Most of the parents also emphasised that it was essential that they were adequately informed and that they were confident about each of the tests in the study (quotation 9, appendix). Some parents suggested that in addition to birthday cards, regular letters or small presents mailed to the children would help to make the study more appealing to the children. Some of the parents of healthy children criticised what they considered to be an unreasonable waiting time in connection with their scheduled visits. In return for their efforts in connection with the study, they expected to be met by a well-prepared and reasonably grateful study team. This non-deferential attitude among the parents of healthy children was the only consistent difference in attitude between the parents of healthy children and those with disease.

\section{DISCUSSION}

This study describes a group of parents who have been actively engaged in an extremely demanding and comprehensive clinical study. The results suggest that it is possible to design and accomplish invasive clinical research with children in a manner that parents find ethically sound. One of the main findings was that parents considered participation in COPSAC to be the best possible choice for their children. The tendency of patients to believe that the various trial procedures were intended to benefit them personally has been termed "therapeutic misconception". ${ }^{14}$ This misconception has been documented in numerous studies showing that patients of all kinds are prone to confuse research with treatment. ${ }^{15}$ All the parents in this study, however, were well aware that some of the tests and procedures were given only to advance research, and they did not confuse research with treatment. Nevertheless, the parents perceived the treatment regimens provided by the CRU to be more coherent and up to date than treatments given by their general practitioner. Whether or not children receive better medical care by participating in COPSAC is a complex question beyond the scope of this article.

The parents in this study also valued the benefit of being closely associated with a specific medical centre that is familiar with their children and their medical history. This perceived benefit does not seem to be another therapeutic misconception, but rather seems to reflect the wish of parents to have direct access to medical expertise. As in other studies on motivational factors, ${ }^{16-20}$ most parents were also motivated by altruism.

Although the parents of the healthy children were less tolerant about waiting time and other inconveniences in relation to the scheduled visits at the CRU, they did not differ from the other parents in any other way. The fact that all the mothers in this study had a history of asthma seems to explain why they were highly motivated for their children to participate in COPSAC, regardless of the actual health status of their child. Only a few of the parents in this study subsequently said that they would refuse the early lungfunction test if another child of theirs were to be enrolled in 
COPSAC. This finding corroborates the results from a questionnaire survey, including $92 \%$ of the 402 parents of the COPSAC cohort whose children underwent the early lung-function test. Parental acceptance of the test was indicated by a standard grade from 1 (totally unacceptable) to 10 (fully acceptable). The mean value was found to be 8 and only $13 \%$ of the parents rated acceptability as $\leqslant 5 .{ }^{21}$ Most complaints were related to sedation-that is, both the administration of the sedative and the principle of sedating healthy infants. Hayden $e t$ al $^{22}$ also found that most parents did not find the lung-function test itself distressing and that most of the problems reported were caused by sedation.

The ethics of venepuncture in relation to research on children has also been debated in the literature. ${ }^{23-25}$ Many parents said that they would withdraw from the study if their child responded negatively to the visits to the CRU. From the perspective of the parents, however, a child's momentary discomfort caused by venepuncture did not disqualify the COPSAC project as such. Although it is obvious that we need to distinguish between the protests of a toddler who resists leaving a toy in the waiting room to go into the research room and the protests of a toddler who is frightened of the research apparatus, ${ }^{26}$ it is less evident whether and when it is legitimate to over-ride an objection of the second type. In our study, it seemed that the parents would balance the discomfort caused by a test with its potential benefit (to research as well as to the child), and they would eventually decide whether or not their toddler's objections should qualify as dissent. Consequently, it is essential to discuss with the parents the consequences of refusing a specific test, to avoid parents putting unreasonable pressure on their child to complete a specific test. Our study suggests that it is possible to design and accomplish invasive clinical research with healthy children in a manner that parents find ethically sound.

The generalisability of this study may be limited owing to the small sample size. Nevertheless, the conclusions of this study are strengthened by the fact that its findings were quite consistent, although the parents were deliberately broadly sampled. The long-term participation of the participants in COPSAC also suggests that the positive attitude described in this study may be prevalent among the parents associated with it. As the mothers were informed at the time of the interview that their statements would be anonymised, and that the interviewer was neither a doctor nor part of the COPSAC staff, this positive attitude is not likely to be caused by their possible wish to please the COPSAC staff. All the mothers of children participating in COPSAC had a medical history of asthma, which might have increased their motivation for their children to participate in research. In consequence, the views on research of this highly motivated population may differ from the views of the population of healthy parents with healthy children.

Regrettably, the study describes the perceptions of only those parents who chose to let their children participate in COPSAC. Although we also intended to include parents who declined to enrol their children and parents who later withdrew their children, the regional research ethics committee would not allow us to include them in our study. Those parents would probably be more critical towards COPSAC and towards research on children in general. If possible, future studies should also include those parents, and it would also be relevant to analyse COPSAC from the perspective of the children who participate in the study.

\section{ACKNOWLEDGEMENTS}

We thank the parents who participated in this study; Malene Starup Stage for helping to access the COPSAC database; and Michael Norup, Flemming Binderup Gammelgaard, Dorthe Goldschmidt, Peter Rossel and Sigurd Lauridsen for review and comments on the manuscript.

\section{What is already known on this topic}

Although paediatric research is necessary to improve medical treatment of children, the participation of children in research has often been considered ethically problematic.

\section{What this study adds}

Our study of the perceptions of parents on the participation of their children in a comprehensive and invasive birth cohort study suggests that it is possible to design and accomplish invasive clinical research on children in a manner that parents find ethically sound.

\section{Authors' affiliations}

A Gammelgaard, Department of Medical Philosophy and Clinical Theory, Institute of Public Health, University of Copenhagen, Copenhagen N, Denmark

L E Knudsen, Department of Environmental Medicine, Institute of Public Health, University of Copenhagen, Copenhagen, Denmark

H Bisgaard, Danish Paediatric Asthma Centre, Department of Paediatrics, Copenhagen University Hospital, Gentofte, Copenhagen, Denmark

Funding: This study was supported by the Danish Pediatric Asthma Centre, the Research Centre for Environmental Health (ISMF) contract no 0-302-02-3/7, the CHILDRENGENONETWORK (QLK4-CT-200202198), Aase \& Ejnar Danielsens Fund and the Lippmann Fund. The funders had no involvement in this work.

Competing interests: None declared.

\section{REFERENCES}

1 Burns JP. Research in children. Crit Care Med 2003;31:S131-6.

2 Koren G, Kearns GL, Reed M, et al. Use of healthy children as volunteers in drug studies: the ethical debate. Clin Pharmacol Ther 2003;73:147-52.

3 Food and Drug Administration. Modernization Act of 1997. Pub L 105-115 (1997).

4 National Institutes of Health. NIH policy and guidelines on the inclusion of children as participants in research involving human subjects, 1998.

5 Department of Health and Human Services, Public Health Service, Food and Drug Administration. 63 Federal Register 66632. Regulations requiring manufacturers to assess the safety and effectiveness of new drugs and biological products in pediatric patients, part II, final rule. 21 CFR Parts 201, 312,314 and 601 [Docket no 97N-0165]. RIN 0910-AB20, 1998.

6 Proposal for a regulation of the European parliament and of the Council on medicinal products for paediatric use and amending Council regulation (EEC) no 1786/92, Directive 2001/83/EC and regulation (EC) no 726/2004. Extended impact assessment. \{COM(2004)599 final\}, 2004.

7 Ross LF. Do healthy children deserve greater protection in medical research? J Pediatr 2003; 142:108-12.

8 Rossi WC, Reynolds W, Nelson RM. Child assent and parental permission in pediatric research. Theor Med Bioethics 2003;24:131-48.

9 Wendler D, Shah S. Should children decide whether they are enrolled in nonbeneficial research? Am J Bioethics 2003;3:1-7.

10 Bisgaard H. The Copenhagen Prospective Study on Asthma in Childhood (COPSAC): design, rationale, and baseline data from a longitudinal birth cohort study. Ann Allergy Asthma Immunol 2004;93:381-9.

11 Kvale S. Interviews: an introduction to qualitative research interviewing. London: Sage, 1996.

12 Crabtree BF, Miller WL, eds. Using codes and code manuals: a template organizing style of interpretation. Doing qualitative research. Newbury Park, CA: Sage, 1999

13 King N. Using templates in the thematic analysis of text. In: Cassell C, Symon G, eds. Essential guide to qualitative methods in organizational research. London: Sage, 2004.

14 Appelbaum P, Roth L, Lidz C. The therapeutic misconception: informed consent in psychiatric research. Int J Law Psychiatry 1982;5:319-29.

15 Dresser R. The ubiquity and utility of the therapeutic misconception. Soc Philos Policy 2002;19:271-94.

16 Harth SC, Thong YH. Sociodemographic and motivational characteristics of parents who volunteer their children for clinical research: a controlled study. BMJ 1990;300:1372-5. 
17 Hayman RM, Taylor BJ, Peart NS, et al. Participation in research: informed consent, motivation and influence. J Paediatr Child Health 2001;37:51-4. 18 Langley JM, Halperin SA, Mills EL, et al. Parental willingness to enter a child in a controlled vaccine trial. Clin Invest Med 1998;21:12-16.

19 Rothmier JD, Lasley MV, Shapiro GG. Factors influencing parental consent in pediatric clinical research. Pediatrics 2003;111:1037-41.

20 van Stuijvenberg $M$, Suur MH, de Vos S, et al. Informed consent, parental awareness, and reasons for participating in a randomised controlled study. Arch Dis Child 1998;79:120-5.

21 Loland L. Lung function in infants [PhD dissertation]. Copenhagen: Faculty of Health Sciences, University of Copenhagen, 2003.

22 Hayden MJ, Wildhaber JH, LeSouef PN. Parental attitudes toward infant pulmonary function testing. Pediatr Pulmonol 1998;25:309-13.

23 Shah VS, Al Khannan M, Quinn MW, et al. Is venepuncture in neonatal research ethical? Arch Dis Child Fetal Neonatal Ed 1997;77:F141-2.

24 Humphrey GB, Boon CMJ, van Linden van den Heuvell GFEC, et al. The occurrence of high levels of acute behavioral distress in children and adolescents undergoing routine venipunctures. Pediatrics 1992;90:87-91.

25 Duff AJ. Incorporating psychological approaches into routine paediatric venepuncture. Arch Dis Child 2003;88:931-7.

26 Weithorn LA, Scherer DG. Children's involvement in research participation decisions: psychological considerations. In: Grodin MA, Glantz LH, eds. Children as research subjects - science, ethics, and law. New York: Oxford University Press, 1994.

\section{APPENDIX: EXCERPTS FROM INTERVIEWS Reactions from parents and research team if a child refuses to cooperate}

1. They [the staff] say that they accept the fact that some children are unwilling to participate. The children should want to return again in 6 months, and one has to respect them as individuals.

(i8, mother of a healthy 3-year-old girl).

2. R: Well, then we have to come back another time and try again. And I feel a bit guilty because I use them a great deal, and if they can use him in some research-oriented way, and it doesn't work out because he's unwilling to do the things he's asked, then I feel a little guilty. It's unbelievable how much they help him, so I'd like him to help them too.

Q: How does the staff deal with that?

R: They take it very well, I think. "We'll do it the next time", is what they say.

(i16, mother of a 3-year-old boy diagnosed with asthma)

\section{The early lung-function test}

3. I thought that it was too much. To put a tiny little baby to sleep like that, it was very uncomfortable, I didn't like it. Also because I kept thinking, how necessary is this? For the sake of research, to put my healthy child to sleep and subject him to this. Suddenly it seemed so wrong.

(il, mother of a healthy 4-year-old boy)

4. Even though they'd explained to me what was supposed to happen, I had no idea what was going on ... I mean, I knew that they were testing lung function, and that they were trying to provoke the lungs or something like that. She was put on a table, and they started explaining: "Now we're going to put a mask on her, so that she will fall asleep." Once the mask was on, and she was lying there with that squeezejacket on and all the different equipment, heart monitors and so on-she looked most of all, like you imagine what people look like when they're dying. And when they blew air down into her lungs, you could see how her chest rose. That was an overwhelming experience, I think. Afterwards, an hour or so went by before she woke up again. You're sitting there holding your child in your arms and you can't do anything. (i6, mother of a healthy 4-year-old girl)

\section{Parents' views on research with children}

5. R: I'm willing to accept that a lot of the things that were done were for the sake of research. I look at it as though I'm trading with them: Alright, you get to stick and poke and all that. In return, you give my child a quality of treatment that I don't think she can get anywhere else. But if she hadn't needed treatment, I'm sure my attitude would have been completely different.

Q: If she'd been one of the healthy kids? There are a lot of them in the study too.

R: I wouldn't have pulled out of the study, but I'd have felt, I don't know if you can say it, that it would have been more of a shame for her. That she'd have paid more than she's done today. Today, she's gotten more out of it than she paid, I think.

(i19, mother of a 2-year-old girl diagnosed with asthma and atopic dermatitis)

6. Sometimes I think the debate surrounding research gets to the point of hysteria. With blood tests, for example, you've got the EMLA patch, and there isn't a kid in COPSAC who gets a blood test taken like that [she snaps her fingers], without even knowing it. You can always put a patch on your kid's arm, and as they get older, you can talk to them about it. They're not suffering in any way. Nobody is using force against them.

(i2, mother of a 4-year-old boy diagnosed with asthma and atopic dermatitis)

7. Q: What if he all of a sudden doesn't want a blood test taken? It's one thing to have one taken to diagnose an infection, when it's for his own good. What if they want to take a blood test for something research-related and he won't go along with it?

R: I wouldn't differentiate between a test to measure the degree of infection or if COPSAC needed a blood test, for example, for genetic tests. It wouldn't matter, because I'm pretty tough there, and I'd be thinking long term. The boy has a disease that he will have to deal with for the rest of his life. He's going to be stuck with needles so often that he's going to have to learn to live with it. And we're talking about a few seconds here. His life's going to be tough, he's a sick boy. Sometimes you're going to get stuck with a needle, that's just the way it is.

(i16, mother of a 3-year-old boy diagnosed with asthma and atopic dermatitis)

8. I hope that they learn something, but I know that the results won't help my children. They do get thoroughly checked out by this, though. Of course, there were things that they didn't have to check them for. But that's the way it is when you're involved in a project like this, you've got to take the bitter with the sweet.

(il8, mother of a healthy 4-year-old boy)

9. In principle, I'm okay with the COPSAC studies, as long as the parents are included every step of the way. This means, of course, that as parents we're always aware of what's going on, and where we'll draw the line if need be. Nobody knows my child better than I do, so from the project's side, they have to understand that it's us who decide what's acceptable, because we're the ones who can feel when the limit has been reached. I can get my child to go along with a lot by turning it into a game, by making it a positive experience, and by talking about it. I can get him to go along with things that he might not have at first. This means, however, that I can also feel when he says no and won't go any further. Then it has got to be okay to set a limit.

(i20, mother of a healthy 4-year-old boy) 